\title{
A 700 year record of Southern Hemisphere extratropical climate variability
}

\author{
Paul A. MAYEWSKI, ${ }^{1}$ Kirk A. MAASCH, ${ }^{1}$ James W. C. WHITE, ${ }^{2}$ Eric J. STEIG, ${ }^{3}$ \\ Eric MEYERSON, ${ }^{1}$ Ian GOODWIN, ${ }^{4}$ Vin I. MORGAN, ${ }^{5}$ Tas VAN OMMEN, ${ }^{5}$ \\ Mark A. J. CURRAN, ${ }^{5}$ Joseph SOUNEY, ${ }^{6}$ Karl KREUTZ ${ }^{1}$ \\ ${ }^{1}$ Climate Change Institute, University of Maine, 303 Bryand Global Sciences Center, Orono, ME 04469, USA \\ E-mail: paul.mayewski@maine.edu \\ ${ }^{2}$ Institute for Arctic and Alpine Research, University of Colorado, Boulder, CO 80309, USA \\ ${ }^{3}$ Quaternary Research Center and Department of Earth and Space Sciences, University of Washington, Box 351360, Seattle, \\ WA 98195-1360, USA \\ ${ }^{4}$ School of Environmental and Life Sciences, University of Newcastle, Callaghan, 2308 New South Wales, Australia \\ ${ }^{5}$ Antarctic CRC and Australian Antarctic Division, Private Bag 80, Hobart, Tasmania 7001, Australia \\ ${ }^{6}$ Institute for the Study of Earth, Oceans and Space, University of New Hampshire, Durham, NH 03824, USA
}

\begin{abstract}
Annually dated ice cores from West and East Antarctica provide proxies for past changes in atmospheric circulation over Antarctica and portions of the Southern Ocean, temperature in coastal West and East Antarctica, and the frequency of South Polar penetration of El Niño events. During the period AD 1700-1850, atmospheric circulation over the Antarctic and at least portions of the Southern Hemisphere underwent a mode switch departing from the out-of-phase alternation of multi-decadal long phases of EOF1 and EOF2 modes of the $850 \mathrm{hPa}$ field over the Southern Hemisphere (as defined in the recent record by Thompson and Wallace, 2000; Thompson and Solomon, 2002) that characterizes the remainder of the $\mathbf{7 0 0}$ year long record. From AD 1700 to 1850, lower-tropospheric circulation was replaced by in-phase behavior of the Amundsen Sea Low component of EOF2 and the East Antarctic High component of EOF1. During the first phase of the mode switch, both West and East Antarctic temperatures declined, potentially in response to the increased extent of sea ice surrounding both regions. At the end of the mode switch, West Antarctic coastal temperatures rose and East Antarctic coastal temperatures fell, respectively, to their second highest and lowest of the record. Polar penetration of El Niño events increased during the mode switch. The onset of the AD 1700-1850 mode switch coincides with the extreme state of the Maunder Minimum in solar variability. Late 20th-century West Antarctic coastal temperatures are the highest in the record period, and East Antarctic coastal temperatures close to the lowest. Since AD 1700, extratropical regions of the Southern Hemisphere have experienced significant climate variability coincident with changes in both solar variability and greenhouse gases.
\end{abstract}

\section{INTRODUCTION}

Compared to most areas on Earth, the vast continent of Antarctica has been, except for the most recent decades, a minor focus of scientific exploration. Yet what is already known about Antarctica demonstrates that, despite its remote location, it plays a significant role in the global climate system. Encircled by some of the world's most biologically productive oceans, Antarctica is the largest reservoir of fresh water on the planet, a major site for the production of the cold deep water that drives ocean circulation, a major player in Earth's albedo dynamics, and an important driving component for atmospheric circulation. Thus, Antarctica plays a critical role in the dynamic linkages that couple the spatially and temporally complex components of Earth's climate system. While the complexity of the global climate system is now widely appreciated, the details of its functioning are still poorly understood. In the Northern Hemisphere and portions of the Southern Hemisphere, direct observational and instrumental records exist only for the last $\sim 2000$ and $\sim 100$ years, respectively. Except at a small handful of coastal sites, observational and instrumental records in Antarctica cover only the last 40-50 years.
The Antarctic Oscillation (AAO), also referred to as the High Latitude Mode, and the Southern Hemisphere Annular Mode (Kidson, 1988; Thompson and Wallace, 2000; Thompson and Solomon, 2002) are expressions of the statistically dominant temporal variability over the extratropical regions of the Southern Hemisphere. The AAO is a near-zonally symmetric seesaw in atmospheric mass between high and mid-latitudes and is characterized by variations in the strength and extent of the subpolar wind maximum (the polar vortex). Its manifestation in the mean sea-level pressure field is revealed in the US National Centers for Environmental Prediction (NCEP) Re-analyses (NNR) covering the period 1948-2001 (Thompson and Wallace, 2000; www.jisao. washington.edu) (Fig. 1a). Over at least the period of the instrumental era, the AAO is a prominent feature. Warming (expanding) Hadley circulation in the tropics acts to increase the strength of the zonal mean circulation, leading to a strengthening of the polar vortex and consequent isolation of the polar regions, while tropical cooling (shrinking) acts to weaken the polar vortex, allowing more meridional flow and a stronger connection between polar and mid-latitude regions (Shulmeister and others, 2004).

Although the AAO is a prominent mode of variability, it is supplemented by wave patterns across, for example, the 


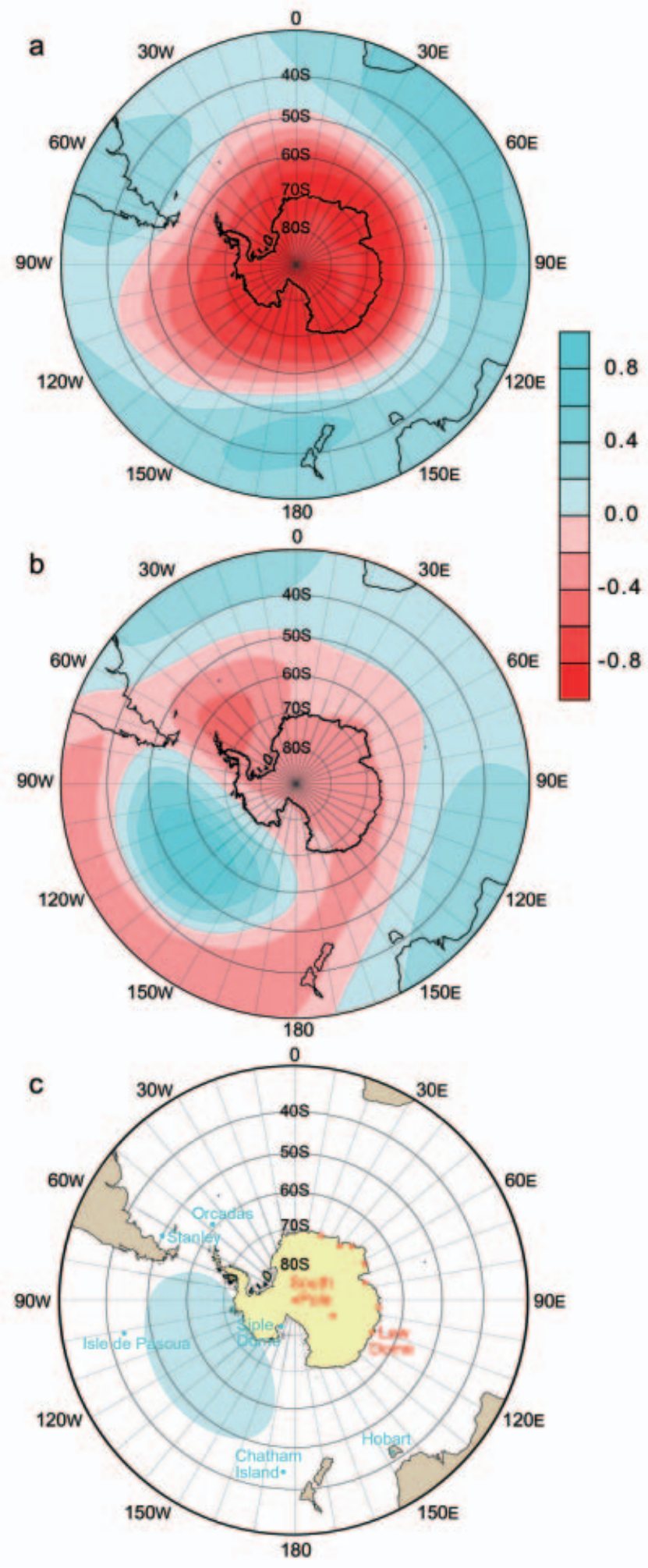

Fig. 1. (a) EOF1 and (b) EOF2 of the Southern Hemisphere extratropical $850 \mathrm{hPa} Z$ (plotted as correlations) taken from www.jisao.washington.edu (Thompson and Wallace, 2000; Thompson and Solomon, 2002). (c) Regions and sites where sealevel pressure is strongly correlated with either DSS $\mathrm{Na}$ (red dots) or SD Na (blue area; SD designated by blue dot), plus location of South Pole (red dot at South Pole).

Pacific/South American sector (Mo and Higgins, 1998; Renwick and Revell, 1999). NNR calculations reveal a seesaw between the South Pacific and Antarctica across to the southwestern Atlantic that represents the second dominant mode of circulation for the extratropics (Thompson and Wallace, 2000) (Fig. 1b). Persistence and position of the Amundsen Sea Low (ASL), the South Pacific component of the seesaw, is associated with meridional circulation south of New Zealand imposed by the presence of the Australian land mass (Sturman and Tapper, 1996; Hurrell and others, 1998). The Pacific-South American (PSA) mode of this seesaw may be forced by anomalous tropical heating (convection) associated both with the El-Niño-Southern Oscillation (ENSO) cycle and with shorter-term intra-seasonal variability (Kiladis and Mo, 1998; Mo and Higgins, 1998). The PSA has a strong influence on blocking anticyclone activity across the southeast Pacific.

The present-day climate of the Antarctic exhibits significant regional complexity that is closely linked to changes in global climate (Yuan and others, 1996). Slight cooling of much of the Antarctic ice sheet, observed from in situ and satellite temperature measurements during the period 197998 (Comiso, 2000), contrasts with warming over the Antarctic Peninsula during the same period (Jacobs and Comiso, 1997). They may also be linked to alternating warm and cold anomalies and associated changes in sea-ice extent around the continent, consistent with the presence of eastward-propagating temperature patterns generated by the Antarctic Circumpolar Wave (ACW) (White and Peterson, 1996). An associated feature, the Antarctic Dipole (ADP), characterized by out-of-phase relationships in sea-ice extent, temperature and sea-level pressure, between Atlantic and Pacific sectors, is connected with extratropical features such as ENSO (Chiu, 1983; Carleton, 1989; Simmonds and Jacka, 1995; Ledley and Huang, 1997; Peterson and White, 1998; Harangozo, 2000; Yuan and Martinson, 2000, 2001; Schneider and Steig, 2002). It has also been suggested that changes in ozone in the lower stratosphere trigger changes in the acceleration of the westerly winds surrounding Antarctica, thus affecting tropospheric trends in temperature (Thompson and Solomon, 2002). However, to understand the significance of trends and other climate changes on time-scales longer than interannual, and to potentially predict future changes in atmospheric circulation and temperature over Antarctica requires examination of climate series that are longer than available instrumented records. Such records are available from ice cores recovered from Earth's largest storehouse of annually resolved climate records, the Antarctic.

To contribute to the understanding of past climate over the extratropical regions of the Southern Hemisphere, we utilize three of the highest-resolution (sub-annual) ice-core records (Fig. 1c) available from West (Siple Dome) and East Antarctica (Law Dome and South Pole). Siple Dome (SD; $81^{\circ} 39^{\prime} \mathrm{S}, 148^{\circ} 49^{\prime} \mathrm{W}$; elevation $650 \mathrm{~m}$; mean annual accumulation rate $13.3 \mathrm{~cm}$ ice equivalent $\mathrm{a}^{-1}$ ) is located on the Siple Coast, in the Pacific Ocean sector of West Antarctica. Law Dome (Dome Summit South (DSS); $66^{\circ} 46^{\prime} \mathrm{S}, 112^{\circ} 48^{\prime} \mathrm{E}$; elevation $1370 \mathrm{~m}$; mean annual accumulation rate $60 \mathrm{~cm}$ ice equivalent $\mathrm{a}^{-1}$ ) is located in Wilkes Land, in the Indian Ocean sector of East Antarctica (Morgan and others, 1997). SD and DSS ice cores both have annually dated (Van Ommen and Morgan, 1996; Kreutz and others, 2000) proxies for changes in sea-level pressure and temperature. The South Pole (elevation 2814 m; mean annual accumulation rate $8 \mathrm{~cm}$ ice equivalent $\mathrm{a}^{-1}$ ) ice core contains an annually dated proxy for El Niño frequency covering the last 500 years (Meyerson and others, 2002). 


\section{VARIABILITY IN ATMOSPHERIC CIRCULATION}

To assess variability in atmospheric circulation, we examine sea-level pressure ice-core calibrated proxies developed from the SD and DSS ice cores (Fig. 2).

Higher (lower) levels of sea-salt deposition (represented by $\mathrm{Na}$ ) at SD are coincident with higher (lower) levels of austral winter-spring cyclone intensity in one of the major quasi-stationary lows in the circumpolar trough, the ASL (Kreutz and others, 2000). Annual values of $\mathrm{Na}$ in the SD ice core are anticorrelated ( $r=-0.32$ (annual series) to -0.51 to -0.75 (3 year smoothed series); $p<0.001$ ) with SeptemberOctober-November SLP changes throughout much of the South Pacific (including New Zealand, South America and the Antarctic Peninsula) (Fig. 1c) over the period of ice-core and instrumental overlap (1900-95) (Kreutz and others, 2000).

Higher (lower) levels of sea-salt deposition (represented by $\mathrm{Na}$ ) at DSS are associated with high (low) sea-level pressure changes from coastal and interior East Antarctic locations (Souney and others, 2002) and with increased (decreased) wind speeds at Casey Station, coastward of DSS (Curran and others, 1998). The high sea-salt loading of the poleward-moving air masses is coincident with the austral winter minimum in sea ice (June). The correlation is best for June because there is at this time an available source of sea salt from open water and also energetic air-sea exchange allowing entrainment of sea-salt aerosols. Annual values of $\mathrm{Na}$ in the DSS ice core are well correlated $(r=0.35-0.636$; $r$ average for 11 stations (Fig. 1c); $p<0.05$ ) with winter (June correlation highest) sea-level pressure over East Antarctica during the period of ice-core and instrumental overlap (1957-96), providing a proxy for the East Antarctic High (EAH) (Souney and others, 2002).

The SD and DSS proxies for the ASL and EAH, respectively, were resampled using a 25 year running mean in order to examine multi-decadal scale variability (Fig. 2). Testing demonstrated that use of the 25 year running mean did not introduce phasing artifacts into the data. Comparison between the location of the instrumental-ice-core calibration sites (Fig. 1c) and the regional distribution of the first two primary modes of temporal behavior at $850 \mathrm{hPa}$ (Fig. 1a and b, after Thompson and Wallace, 2000) demonstrates that the instrumental-ice-core calibration sites are distributed throughout regions representative of two major Southern Hemisphere extratropical circulation seesaws: (1) the AAO (Fig. 1a), and (2) the ASL-EAH and associated PSA (Fig. 1b).

Between AD 1200 and 1700, long-term, multi-centennial scale trends in the ASL and EAH are inverse, with the EAH generally weakening and the ASL generally intensifying (Fig. 2). These trends suggest poleward migration of the circumpolar trough consistent with solar-insolation-induced deglaciation of Antarctica over the last several thousand years. During this same period the ASL and EAH also display inverse behavior at the multi-decadal scale (Fig. 2). This seesaw pattern maintained between the ASL and EAH from AD 1200 to 1700, at centennial to multi-decadal time-scales, is suggestive of the atmospheric seesaw mode calculated from the AD 1948-2001 NCEP re-analysis data seen in Figure $1 \mathrm{~b}$.

There is a prominent departure from Figure 1b-style behaviour, ASL and EAH seesaw, during the period AD 17001850. During this time the EAH is strong (weak) when the ASL is deep (shallow). The EAH and ASL are weakest

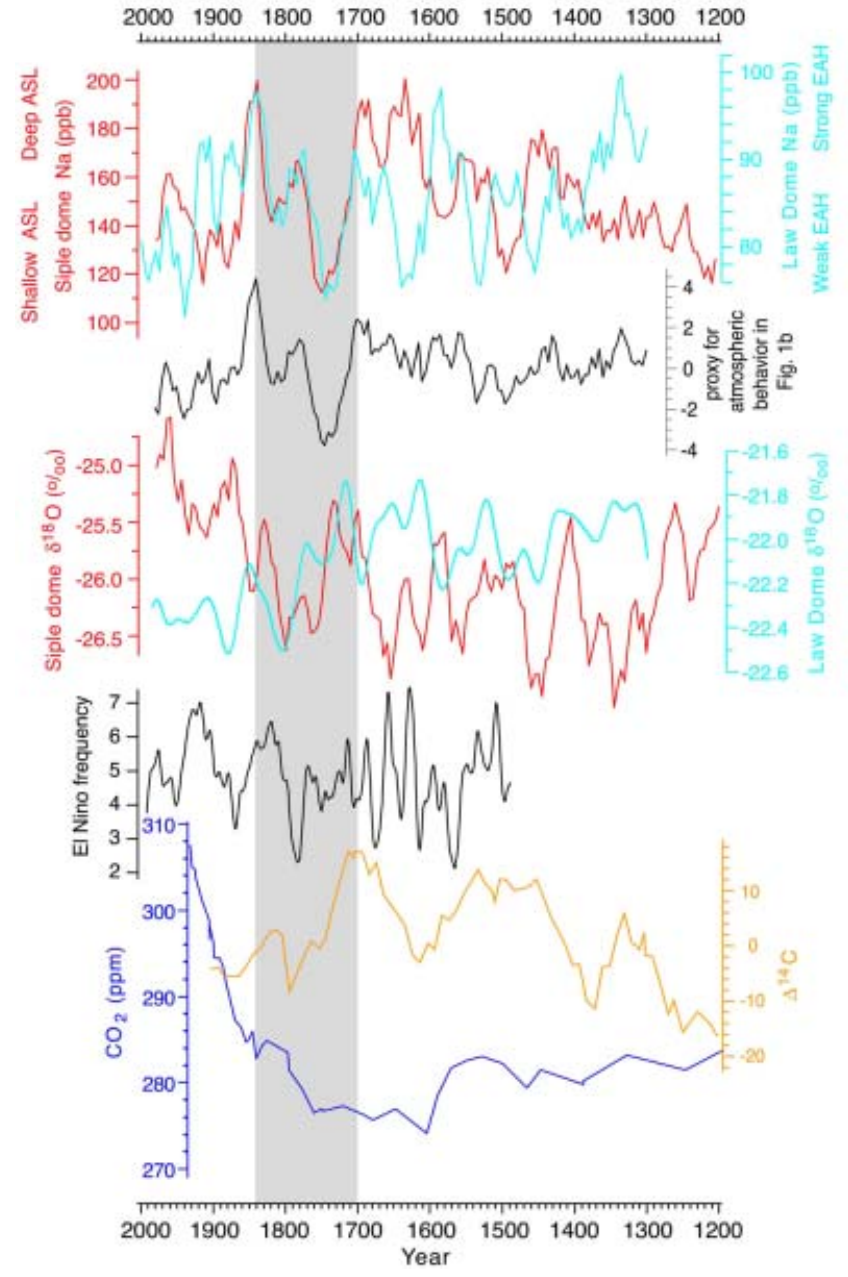

Fig. 2. A 25 year running mean of SD and DSS $\mathrm{Na}(\mathrm{ppb})$ used as a proxy for the ASL and EAH, respectively, with estimated sea-level pressure developed from calibration with the instrumental and NCEP re-analysis (based on Kreutz and others, 2000; Souney and others, 2002). EOF2 (Fig. 1b) proxy (normalized units) based on adding normalized DSS Na plus normalized SD Na. 25 year running mean SD and DSS $\delta^{18} \mathrm{O}(\%)$ used as a proxy for temperature, with estimated temperature developed from calibration with instrumental mean annual and seasonal temperature values (Van Ommen and Morgan, 1997; Steig and others, 2000). Frequency of El Niño polar penetration based on calibration between the historical El Niño frequency record (Quinn and others, 1987; Quinn and Neal, 1992) and SP MS (Meyerson and others, 2002). $\Delta^{14} \mathrm{C}$ series used as an approximation for solar variability (Stuiver and Braziunas, 1993). $\mathrm{CO}_{2}$ from DSS ice core (Etheridge and others, 1998).

$\sim$ AD 1750 and strongest $\sim$ AD 1850, relative to the full record. We suggest that between AD 1770 and 1850 the South Pacific (and perhaps the entire Southern Ocean) and Antarctica experienced a mode switch. Decreased Na concentrations $\sim$ AD 1700 may be a consequence of dramatically increased extent and duration of sea ice and, as a consequence, significant loss of exposed $\mathrm{Na}$ source area. Alternately, the decreased $\mathrm{Na}$ concentrations may mark a period of weakened ASL and EAH and therefore reduced incorporation of Na. Increased Na levels AD 1850 suggest decreased sea-ice extent and duration and/or strengthened ASL and EAH. Following the AD 1700-1850 mode switch, the multidecadal scale behavior of the ASL and EAH returns to its preAD 1700 mode. 
To assess past variability in temperature between coastal sites in East and West Antarctica we examine the $\delta^{18} \mathrm{O}$ icecore proxy for temperature derived from the SD and DSS ice cores (Fig. 2). The average form of the seasonal $\delta^{18} \mathrm{O}$ curve at DSS is calibrated with measured temperature at the site, resulting in the relationship $0.44 \%{ }^{\circ} \mathrm{C}^{-1}$ (Morgan and Van Ommen, 1997; Van Ommen and Morgan, 1997). For the calibration between SD $\delta^{18} \mathrm{O}$ and temperature we utilize a relationship available for the western side of the Ross Ice Shelf derived from the Taylor Dome ice core of $0.5 \%{ }^{\circ} \mathrm{C}^{-1}$ (Steig and others, 2000).

Examination of the 25 year running mean values for the SD and DSS ice-core temperature proxies demonstrates that these two sites differ in their long-term, multi-centennial scale trends over most of the record. This difference in longterm temperature trend is not necessarily maintained at the multi-decadal scale as is the case for the pre-AD 1700 and post-AD 1850 portions of the ASL and EAH proxy record. For $\mathrm{SD}$ the lowest temperatures (up to $-3^{\circ} \mathrm{C}$ relative to $\mathrm{AD} 1900$ ) are $A D 1350$ and $\sim A D 1450$, and for DSS the lowest temperatures (close to $-2{ }^{\circ} \mathrm{C}$ relative to $\mathrm{AD} 1900$ ) are early and late 19 th century. SD temperatures fluctuate throughout the record, but rise in general from $A D 1650$ to the present. DSS temperatures fluctuate through much of the record, but decline from $\sim A D 1400$ to the present.

During the early phase of the AD 1700-1850 atmospheric mode switch, coastal West and East Antarctic temperatures decline in general together. Background SD temperature rises almost monotonically as of $\sim A D 1800-50$. The second warmest period in the SD record is in the late 19th century (up to $+1^{\circ} \mathrm{C}$ relative to $\mathrm{AD} 1900$ ) and the warmest (up to $+2^{\circ} \mathrm{C}$ relative to $A D 1900$ ) in the mid-20th century. In contrast, temperatures at DSS since the mid-19th century are close to the lowest over the record period. Recent differences between SD and DSS temperatures may be attributed to the influence of 20th-century warming at low latitudes since low-latitude temperature changes may propagate to West Antarctica through the strong teleconnection between the tropical and the southern Pacific (Gereaud and Battisti, 1999). This process may have little influence, and may even promote cooling, in East Antarctica due perhaps to enhanced downwelling of cooler stratospheric source air over East Antarctica.

\section{EL NIÑO FREQUENCY}

A 500 year long annually dated record of methanesulfonate (MS) from the SP ice core, calibrated with and comparable to the historical El Niño event record (Quinn and others, 1987; Quinn and Neal, 1992), is utilized as a proxy for the frequency of polar penetration of El Niño events (Meyerson and others, 2002). The switch to longer periods of El Niño recurrence close to $\mathrm{AD} 1850$, is coincident with the middle of the AD 1700-1850 mode switch and the onset of rise in temperatures at SD and in general globally. This switch in recurrence of El Niño event penetrations to South Pole further supports a strong link between the tropical Pacific and West Antarctica.

\section{DISCUSSION AND CONCLUSIONS}

The ASL (an approximation of EOF2 mode of the temporal behavior at $850 \mathrm{hPa}$ in the Southern Hemisphere) and the EAH (an approximation of EOF1 mode of the temporal behavior at $850 \mathrm{hPa}$ in the Southern Hemisphere) have operated in a seesaw mode both during the instrumental era (Fig. 1b) and at multi-decadal to multi-centennial scales throughout much of the 700 year period recorded by the DSS and SD ice cores. This behavior was disrupted during a mode switch from $A D 1700$ to 1850 that affected a large portion of the extratropical regions of the Southern Hemisphere. Examination of other paleoclimate records verifies that this climate disruption occurred throughout the Southern Hemisphere, as evidenced by: a shift in circulation at Taylor Dome, Ross Sea region, East Antarctica; drier and colder conditions based on a speleothem record from Cold Air Cave, South Africa (Lee-Thorp and others, 2001); and colder conditions based on an ice core from Huascarán ice cap, Peru (Thompson and others, 1995). The mode switch started during a period of globally distributed cooling, coincident with a 10 ppmv drop in the DSS ice-core $\mathrm{CO}_{2}$ record (Etheridge and others, 1998), and at the height of the Maunder Minimum, identified in the $\Delta^{14} \mathrm{C}$ proxy for solar variability (Lingenfelter, 1963; O'Brien, 1979; Stuiver and Braziunas, 1993) (Fig. 2). During the mode switch, atmospheric circulation patterns were characterized by greater than normal variability relative to the remainder of the record. Increased climate variability appears to be a common theme during cold periods, based on the examination of glacial/interglacial scale records of change in atmospheric circulation (Mayewski and others, 1994).

Generally lower temperature from AD 1350 to the early 19th century in coastal West Antarctica is coincident with increased values of $\Delta^{14} \mathrm{C}$ (Fig. 2) (decreased solar variability) and the onset of a globally distributed cool event, referred to in some regions as the Little Ice Age. Both SD and DSS approximations for coastal West and East Antarctic temperatures, respectively, decrease during the early phase of the AD 1700-1850 mode switch, supporting the idea of increased sea-ice extent (decreased open-ocean source for $\mathrm{Na}$ ) as a cause for the dramatic drop in Na levels in these areas.

SD temperature starts to rise in the early 19th century, at the end of the atmospheric mode switch. The rise in temperature is coincident with an increased frequency of El Niño events that penetrate as far south as the South Pole. Both the late 19th- and a 20th-century increase in SD temperature (of $+2^{\circ} \mathrm{C}$ ) are coincident with rise in $\mathrm{CO}_{2}$ (Fig. 2), and the latter with the trend in instrumental observations of a $0.17^{\circ} \mathrm{C}$ warming in the Southern Ocean over the second half of the 20th century (Gille, 2002). Recently reported decreases in temperature over East Antarctica, for the last few decades (Comiso, 2000; Doran and others, 2002), are consistent with the decrease in temperature at DSS recorded since the mid-19th century. The juxtaposition of warming at SD with ASL values that are within the range of natural variability of the last 700 years suggests that atmospheric circulation is not the sole cause for the warming. However, the low elevation of West Antarctica relative to East Antarctica makes it suitable for the penetration of lower-tropospheric warming events and the intensified frequency of penetration of El Niño events.

Superimposed on the general trends in the SD and DSS proxies for atmospheric circulation and temperature described above are a series of highly significant periodicities $(p<0.01)$ close to $2-8$ years and 10-12 years (Kreutz and others, 2000; Souney and others, 2002) suggestive of ACW and ENSO phenomena and solar cycles, respectively, plus a series of multi-decadal periodicities that may offer insight 
into other atmospheric teleconnections and potential climate forcings. More high-resolution, annually dated records similar to those being collected by the International TransAntarctic Scientific Expedition (ITASE) (Mayewski and Goodwin, 1997) are required to assess the implications of these periodic structures. ITASE ice cores will also help to determine changes in the position of the ASL and EAH over time that cannot be assessed in this study. Examination of paleoclimate archives that capture pre-instrumental-era behavior of major modes of Southern Hemisphere atmospheric circulation are essential to the insight needed to assess the dynamic range and forcing of the global climate system.

\section{ACKNOWLEDGEMENTS}

Support for this research was provided by US National Science Foundation (NSF) Office of Polar Programs (OPP) and Earth System History (ESH) grants NSF OPP 0096305, NSF OPP 00996299 and NSF ESH 0096331.

\section{REFERENCES}

Carleton, A. M. 1989. Antarctic sea-ice relationships with indices of the atmospheric circulation of the Southern Hemisphere. Climate Dyn., 3(4), 207-220.

Chiu, L. S. 1983. Antarctic sea ice variations, 1973-1980. In StreetPerrott, A., M. Beran and R. Ratcliffe, eds. Variations in the global water budget. Dordrecht, D. Reidel Publishing Co., 301-311.

Comiso, J.C. 2000. Variability and trends in Antarctic surface temperatures from in situ and satellite infrared measurements. J. Climate, 13(10), 1674-1696.

Curran, M. A. J., T. D. van Ommen and V. Morgan. 1998. Seasonal characteristics of the major ions in the high-accumulation Dome Summit South ice core, Law Dome, Antarctica. Ann. Glaciol. 27, 385-390.

Doran, P. T. and 12 others. 2002. Antarctic climate cooling and terrestrial ecosystem response. Nature, 415(6871), 517-520.

Etheridge, D. M., L. P. Steele, R. L. Langenfelds, R. J. Francey, J. M. Barnola and V. I. Morgan. 1998. Natural and anthropogenic changes in atmospheric $\mathrm{CO}_{2}$ over the last 1000 years from air in Antarctic firn and ice. J. Geophys. Res., 101(D2), 4115-4128.

Gereaud, R. D. and D.S. Battisti. 1999. Interannual (ENSO) and interdecadal (ENSO-like) variability in the Southern Hemisphere circulation. J. Climate, 12(7), 2113-2123.

Gille, S. T. 2002. Warming of the Southern Ocean since the 1950s. Science, 295(5558), 1275-1277.

Harangozo, S. A. 2000. A search for the ENSO teleconnections in the West Antarctic peninsula climate in austral winter. Int. J. Climatol., 20(6), 663-679.

Hurrell, J. W., H. van Loon and D. J. Shea. 1998. The mean state of the troposphere. In Karoly, D.J. and D. G. Vincent, eds. Meteorology of the Southern Hemisphere. Boston, MA, American Meteorological Society, 1-46.

Jacobs, S.S. and J.C. Comiso. 1997. A climate anomaly in the Amundsen and Bellingshausen Seas. J. Climate, 10(4), 697-711.

Kidson, J.W. 1988. Interannual variations in the Southern Hemisphere. J. Climate, 1(12), 1177-1198.

Kiladis, G. N. and K. C. Mo. 1998. Interannual and intraseasonal vaiability in the Southern Hemisphere. In Karoly, D. J. and D. G. Vincent, eds. Meteorology of the Southern Hemisphere. Boston, MA, American Meteorological Society, 307-336.

Kreutz, K.J., P.A. Mayewski, I.I. Pittalwala, L.D. Meeker, M.S. Twickler and S.I. Whitlow. 2000. Sea level pressure variability in the Amundsen Sea region inferred from a West
Antarctic glaciochemical record. J. Geophys. Res., 105(D3), 4047-4059.

Ledley, T. S. and Z. Huang. 1997. A possible ENSO signal in the Ross Sea. Geophys. Res. Lett., 24(24), 3253-3256.

Lee-Thorp, J.A. and 7 others. 2001. Rapid climate shifts in the southern African interior throughout the mid to late Holocene. Geophys. Res. Lett., 28(23), 4507-4510.

Lingenfelter, R.E. 1963. Production of carbon 14 by cosmic ray neutrons. Rev. Geophys., 1(1), 35-55.

Mayewski, P.A. and I. D. Goodwin. 1997. International TransAntarctic Scientific Expedition (ITASE) '200 years of past Antarctic climate and environmental change': science and implementation plan, 1996. Bern, Past Global Changes. (PAGES Workshop Report Series 97-1.)

Mayewski, P.A. and 13 others. 1994. Changes in atmospheric circulation and ocean ice cover over the North Atlantic during the last 41,000 years. Science, 263(5154), 1747-1751.

Meyerson, E.A., P.A. Mayewski, K.J. Kreutz, L.D. Meeker, S. I. Whitlow and M.S. Twickler. 2002. The polar expression of ENSO and sea-ice variability as recorded in a South Pole ice core. Ann. Glaciol., 35, 430-436.

Mo, K. C. and R.W. Higgins. 1998. The Pacific-South American modes and tropical convection during the Southern Hemisphere winter. Mon. Weather Rev., 126(6), 1581-1596.

Morgan, V. and T.D. van Ommen. 1997. Seasonality in lateHolocene climate from ice-core records. Holocene, 7(3), 351-354.

Morgan, V.I., C.W. Wookey, J. Li, T. D. van Ommen, W. Skinner and M. F. Fitzpatrick. 1997. Site information and initial results from deep ice drilling on Law Dome, Antarctica. J. Glaciol., 43(143), 3-10.

O'Brien, K. 1979. Secular variations in the production of cosmogenic isotopes in the Earth's atmosphere. J. Geophys. Res., 84(A2), 423-431.

Peterson, R. G. and W. B. White. 1998. Slow oceanic teleconnections linking the Antarctic circumpolar wave with the tropical El Niño-Southern Oscillation. J. Geophys. Res., 103(C11), 24,57324,583 .

Quinn, W. H. and V. T. Neal. 1992. The historical record of El Niño events. In Bradley, R. S. and P. D. Jones, eds. Climate since A.D. 1500. London, etc., Routledge, 623-648.

Quinn, W.H., V.T. Neal and S.E. Antúnez de Mayolo. 1987. El Niño occurrences over the past four and a half centuries. J. Geophys. Res., 92(C13), 14,449-14,461.

Renwick, J.S. and M.J. Revell. 1999. Blocking over the South Pacific and Rossby wave propagation. Mon. Weather Rev., 127(10), 2233-2247.

Schneider, D.P. and E.J. Steig. 2002. Spatial and temporal variability of Antarctic ice sheet microwave brightness temperatures. Geophys. Res. Lett., 29(20), 1964. (10.1029/ 2002GL015490.)

Shulmeister, J. and 10 others. 2004. The Southern Hemisphere westerlies in the Australasian sector. Quat. Int., 118-119, 23-53.

Simmonds, I. and T.H. Jacka. 1995. Relationships between the interannual variability of Antarctic sea ice and the Southern Oscillation. J. Climate, 8(3), 637-647.

Souney, J., P. A. Mayewski, I. Goodwin, V. Morgan and T. van Ommen. 2002. A 700-year record of atmospheric circulation developed from the Law Dome ice core, East Antarctica. J. Geophys. Res., 107(D22), 4608-4616. (10.1029/ 2002JD002104.)

Steig, E. J. and 7 others. 2000. Wisconsinan and Holocene climate history from an ice core at Taylor Dome, western Ross Embayment, Antarctica. Geogr. Ann., 82A(2-3), 213-235.

Stuiver, M. and T.F. Braziunas. 1993. Sun, ocean, climate and atmosphere ${ }^{14} \mathrm{CO}_{2}$ : an evaluation of causal and spectral relationship. Holocene, 3(4), 289-305.

Sturman, A.P. and N. Tapper. 1996. The weather and climate of Australia and New Zealand. Melbourne, etc., Oxford University Press. 
Thompson, D. W. J. and S. Solomon. 2002. Interpretation of recent Southern Hemisphere climate change. Science, 296(5569), 895-899.

Thompson, D. W. J. and J. M. Wallace. 2000. Annular modes in the extratropical circulation. Part I: Month-to-month variability. J. Climate, 13(5), 1000-1016.

Thompson, L.G. and 7 others. 1995. Late glacial stage and Holocene tropical ice core records from Huascarán, Peru. Science, 269(5220), 46-50.

Van Ommen, T. D. and V. Morgan. 1996. Peroxide concentrations in the Dome Summit South ice core, Law Dome, Antarctica. J. Geophys. Res., 101(D10), 15,147-15,152.

Van Ommen, T.D. and V. Morgan. 1997. Calibrating the ice core paleothermometer using seasonality. J. Geophys. Res., 102(D8), 9351-9357.

White, B.W. and R. G. Peterson. 1996. An Antarctic circumpolar wave in surface pressure, wind, temperature and sea ice extent. Nature, 380(6576), 699-702.

Yuan, X. and D.G. Martinson. 2000. Antarctic sea ice extent variability and its global connectivity. J. Climate, 13(10), 1697-1717.

Yuan, X. and D.G. Martinson. 2001. The Antarctic dipole and its predictability. Geophys. Res. Lett., 28(18), 36093612.

Yuan, X., M. A. Cane and D. G. Martinson. 1996. Cycling around the South Pole. Nature, 380(6576), 673-674. 